\title{
A Concave H-Shaped Patch Antenna with Improved Bandwidth and Isolation for MIMO Systems
}

\author{
B. Kumara Swamy ${ }^{1}$, S. Anil Kumar ${ }^{1}$, P. D. Vasanth Kumar ${ }^{1}$, N. Yesu Mariyamma ${ }^{1}$ \\ and K. Jagadeesh Babu ${ }^{2}$ \\ ${ }^{1}$ Students of Dept. of ECE, SACET, Chirala, AP, India \\ ${ }^{2}$ Professor, SACET, Chirala, AP, India
}

\begin{abstract}
A compact concaved $H$ - shaped patch antenna for dual-band applications with improved bandwidth and isolation characteristics is presented in this paper. The proposed antenna resonates at multiband of $3.2 \mathrm{GHz}$ and $4.9 \mathrm{GHz}$ frequencies for VSWR $\leq 1.32$, with an impedance bandwidth of $70 \%$. A $2 \times 2$ MIMO system is developed using the proposed antenna giving an excellent isolation of $48 \mathrm{~dB}$ between the two antennas. The developed antenna system can be widely used for the 4G, WLAN and Wi-MAX applications. The proposed antenna is a good choice for MIMO systems operating for several wideband applications.
\end{abstract}

Keywords: Concave H- shaped patch antenna, Impedance bandwidth, Mutual coupling, VSWR

\section{Introduction}

The microstrip patch antenna is one of the most preferred antennas due to its low cost, light weight, simple implementation process and conformability. The microstrip patch antennas radiate primarily because of the fringing fields between the patch edge and the ground plane. However, the general microstrip antennas suffer from narrow bandwidth, which limits their application in modern communication systems like MIMO systems, etc... In recent years the demand for the design of tri-band [1] or multiband antennas is increased, as these antennas can integrate more than one communication standards in a single compact system. In this paper, we propose a Concave H- shaped microstrip patch antenna, giving multiband operation with improved bandwidth and reduced mutual coupling with a simpler structure.

The major problem faced by the MIMO system [2] engineers, when working on small Personal Digital Assistants (PDA) is mutual coupling, which mainly arises due to the smaller spacing between the elements. Usually, in multiple input and multiple output systems the basic aim is to minimize the correlation between the multiple signals. The parameter that describes the correlation between the received signals in highly diversified environments is mutual coupling, which deteriorates the performance of the communication system [3].

The mutual coupling depends on the distance between the elements in a MIMO system. If the distance between the antennas is more, the mutual coupling becomes less and vice versa. However, the distance between the antennas cannot be maintained too large as MIMO systems have their major applications in mobile terminals, laptops, and WLAN access point's wireless communication [4], where size of the device can't be maintained too large. The main source of mutual coupling is surface current flowing through the ground surface. To reduce these surface currents flowing on the ground surface, there are several techniques like Electromagnetic band gap structure [5], defected ground structure [6], decoupling techniques, 
etc... However, all these methods make the design of the antenna more complicated.

In the present work, a Concave H- shaped patch antenna MIMO system is proposed with improved bandwidth and reduced mutual coupling compared to the antenna discussed in [7]. The designed antenna resonates at a multiband of $3.2 \mathrm{GHz}$ and $4.9 \mathrm{GHz}$ with an improved impedance bandwidth of $70 \%$ and the obtained mutual coupling between the antenna elements is small and is less than $-48 \mathrm{~dB}$. In Section 2, the proposed antenna geometry is presented and in Section 3 the two element MIMO array system is presented.

\section{Antenna Design}

As mentioned earlier, the main drawback of patch antenna is narrow bandwidth. Hence, the present work mainly focuses on the improvement of impedance bandwidth. The impedance bandwidth of the patch antennas can be improved by using various techniques like introducing parasitic elements, increasing the thickness of substrate and modifying the shape of the antenna and by introducing slots on the patch. The proposed antenna offers an improved bandwidth of 70\%, which is better than bandwidth obtained in [8] and [9]. The patch antennas are fabricated with various shapes and the most widely designed antennas are E shaped patch antenna, $\mathrm{H}$ shaped patch antenna [10], U slotted patch antennas [11], etc... Among all these antennas, E shaped patch antennas are widely used as they give better performance in terms of both impedance bandwidth and mutual coupling. The antenna proposed in the present work gives better results compared to all the above mentioned antennas in terms of both impedance bandwidth and mutual coupling.

The structure of the proposed antenna is shown in Figure 1. The dimensions of the geometry are given in the Table 1. For better performance, a thick dielectric substrate having a low dielectric constant is desirable as it provides better efficiency, larger bandwidth and better radiation. Here, the substrate selected for the design of the proposed antenna is FR4_epoxy $12.5 \mathrm{~mm}$ and with low permittivity $(\varepsilon r=4.4)$. The dimensions of the substrate are taken as $200 \times 180 \times 12.5 \mathrm{~mm}^{3}$.

Table 1. Dimensions of the proposed antenna

\begin{tabular}{|l|l|}
\hline Parameter & Value(mm) \\
\hline L1 & 3 \\
\hline L2 & 19 \\
\hline L3 & 3 \\
\hline L4 & 5 \\
\hline L5 & 5 \\
\hline L6 & 3 \\
\hline H1 & 10 \\
\hline H2 & 15 \\
\hline H3 & 10 \\
\hline H4 & 2 \\
\hline
\end{tabular}




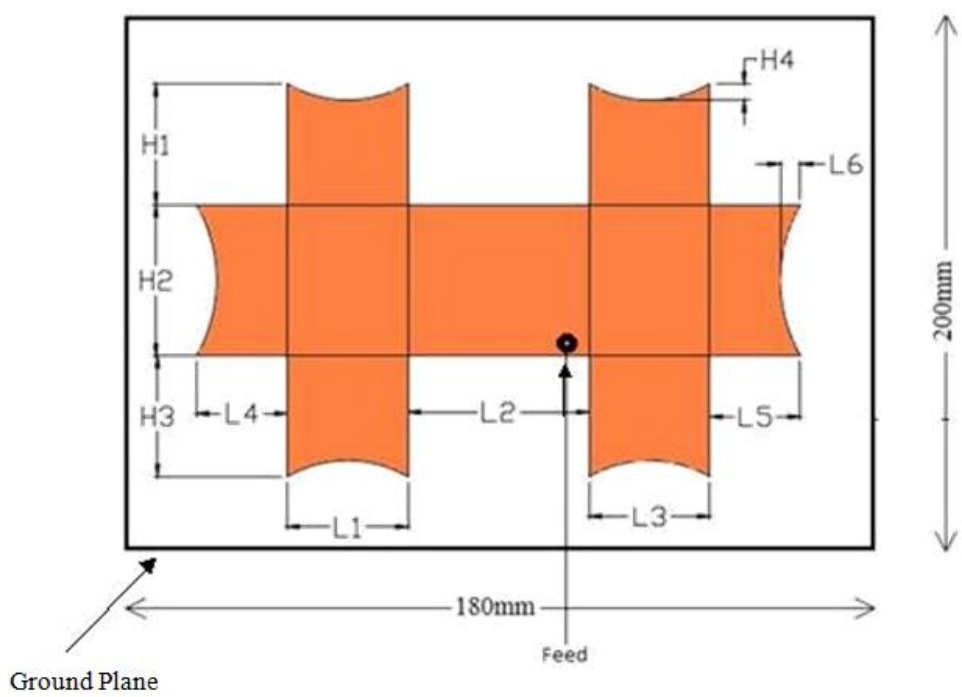

Figure 1. Proposed Concave H- shaped microstrip patch antenna

Microstrip patch antennas can be fed by a variety of methods. These methods are classified into two categories which are contacting (direct) and non-contacting. The four most popular feeding techniques used are microstrip feed, co-axial probe feed, aperture coupled and proximity coupled feeding. Here the whole system is fed by a co-axial probe at the position $\left(\mathrm{X}_{0}, \mathrm{Y}_{0}\right)=(10,27)$ as it is simpler to implement.

The area of the proposed antenna is $38 \times 37 \mathrm{~mm}^{2}$. The left and right arms have same dimensions. The reflection coefficient of the proposed antenna is shown in Figure 2, giving an impedance bandwidth of $70 \%$, resonating at $3.2 \mathrm{GHz}$ and $4.9 \mathrm{GHz}$ frequencies, making the antenna system suitable for many WLAN applications.

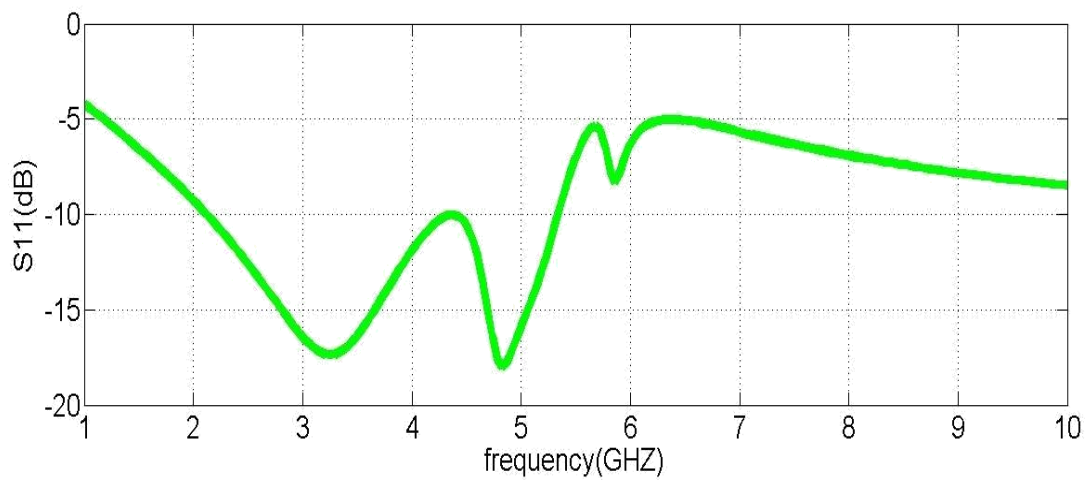

Figure 2. Reflection coefficient of the proposed antenna

\section{Two Element MIMO Array Using the Proposed Antenna}

The main parameter that affects the performance of the MIMO system is mutual coupling. The aim of any MIMO system designer is to reduce the mutual coupling between antennas, when they are closely placed. However, when multiple antennas are involved at closer spacing the design issues are more complicated compared to a SISO (Single Input Single Output) system. The reduction in mutual coupling can be achieved by properly choosing the 
shape of the antenna and without increasing the distance between the elements. The mutual coupling can be minimized by using diversity techniques as explained in [9] and [12].

In the present paper, a $2 \times 2$ MIMO system is developed by using the proposed Curved Hshaped patch antenna as shown in Figure 3. For the proposed MIMO system, the separation between the elements is taken as $10 \mathrm{~mm}$. For the proposed MIMO array, the dimensions are taken same as that of the single Concave H- shaped antenna shown in Figure 1.

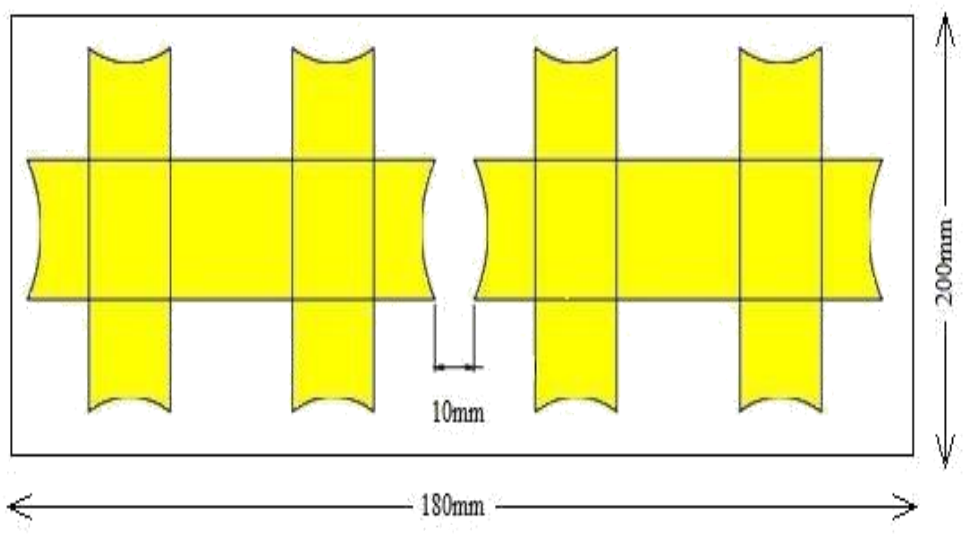

Figure 3. A two element MIMO system using proposed Concave $\mathrm{H}$ - shaped antenna

The Figure 4 shows the simulated results of reflection coefficient and the mutual coupling in $\mathrm{dB}$. The system resonates at a multiband $3.2 \mathrm{GHz}$ and $4.9 \mathrm{GHz}$ with an improved impedance bandwidth of $70 \%(2.1 \mathrm{GHz}$ to $4.37 \mathrm{GHz})$ and the obtained mutual coupling between the antenna elements is small and is less than $-48 \mathrm{~dB}$. Also, the obtained bandwidth by using the proposed antenna is very high compared to the normal E-shaped patch antenna [9]. The return loss of single antenna and their corresponding resonant frequencies and isolation of $2 \times 2$ MIMO system are given in Table 2 .

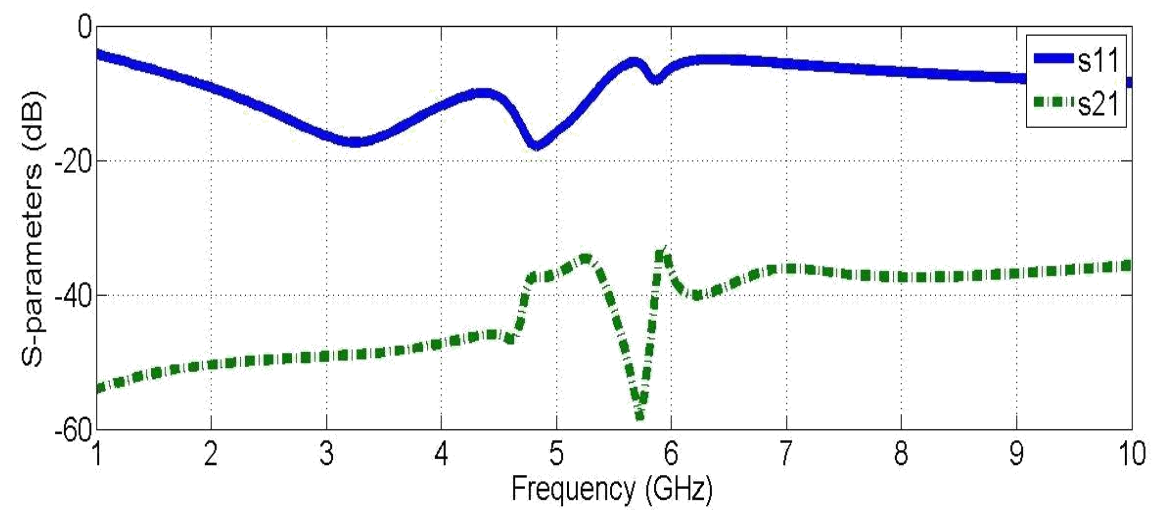

Figure 4. S parameters of proposed Concave $\mathrm{H}$ - shaped microstrip patch antenna 
The VSWR plot of the proposed MIMO array is presented in the Figure 5. The plot gives the desired values of VSWR at the resonant frequencies, which are less than 8. The VSWR value is observed as 1.32 and 1.3 at the resonant frequencies $3.2 \mathrm{GHz}$ and $4.9 \mathrm{GHz}$ respectively, indicating improved matching conditions. The Figure 6 shows the obtained radiation Patterns of the proposed antenna.

Table 2. Return loss and Isolation of the proposed antenna

\begin{tabular}{|l|l|l|l|}
\hline S.No. & $\begin{array}{l}\text { Resonant } \\
\text { Frequency }(\mathbf{G H z})\end{array}$ & $\begin{array}{l}\text { Return } \\
\text { Loss }(\mathbf{d B})\end{array}$ & Isolation(dB) \\
\hline 1. & 3.2 & 17.2 & 48 \\
\hline 2. & 4.9 & 18 & 37.5 \\
\hline
\end{tabular}

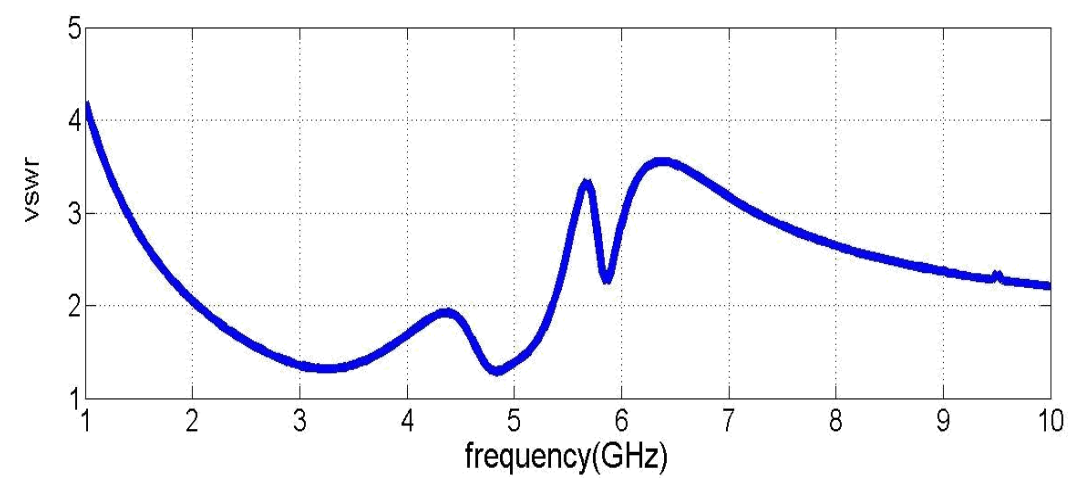

Figure 5. VSWR plot of the proposed Antenna

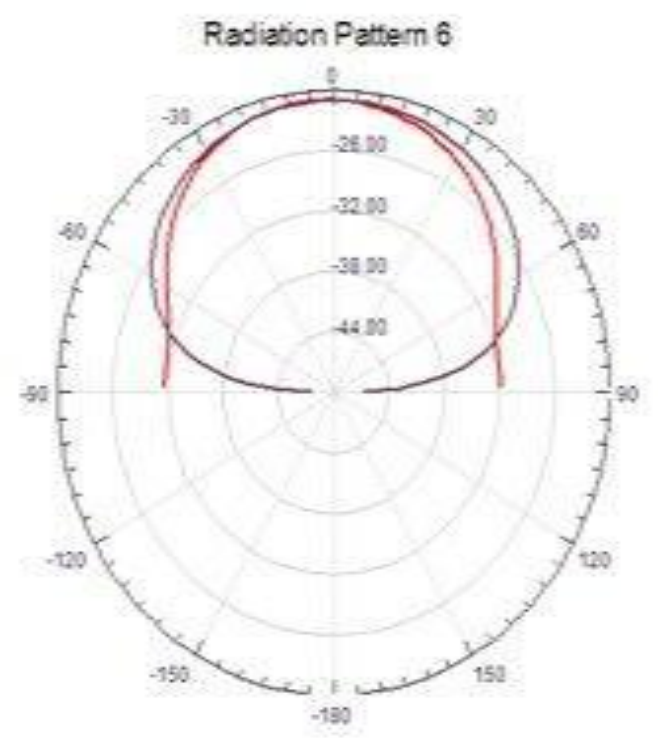

Figure 6. Radiation pattern of the proposed Antenna 


\section{Conclusion}

In this paper, a Concave H- shaped patch antenna is proposed and a two element MIMO array is developed using the proposed antenna. The proposed antenna resonates at a multiband of frequencies $3.2 \mathrm{GHz}$ and $4.9 \mathrm{GHz}$ with an improved impedance bandwidth of $70 \%$ and a reduced mutual coupling of $-48 \mathrm{~dB}$. These characteristics are well suited for all 4G MIMO applications. The proposed study can be extended by employing more number of antennas in MIMO system for improving the channel capacity of the MIMO systems.

\section{References}

[1] K. J. Babu, K. S. R. Krishna and L. P. Reddy, “A triband swastika shaped patch antenna with reduced mutual coupling for wireless MIMO systems", Journal of Electronics (China), SPRINGER, vol. 28, (2011) November, pp. 483-487.

[2] K. J. Babu, K. S. R. Krishna and L. P. Reddy, "A review on the design of MIMO antennas for upcoming 4G communications", International Journal of Applied Engineering Research, Dindigul, vol. 1, no. 4, (2011).

[3] A. A. Abouda and S. G. Hgagman, "Effect of mutual coupling capacity of MIMO wireless channels in high SNR scenario", Progress In Electromagnetics Research, PIER, vol. 65, (2006), pp. 27-40.

[4] M. A. Jensen and J. W. Wallace, "A review of antennas and propagation for MIMO wireless communications", IEEE Trans. Antennas Propagation, vol. 52, (2004) November, pp. 2810-2824.

[5] F. Caminita, S. Costanzo, G. DiMassa, G. Guarnieri, S. Maci, G. Mauriello and I. Venneri, "Reduction of patch antenna coupling by using a compact EBG formed by shorted strips with interlocked branch stubs", IEEE Antennas and Wireless Propagation Letters, vol. 8, no. 1, (2009), pp. 811-814.

[6] F. Fan and Zehongyan, "Compact band pass filter with spurious pass band suppression using defected ground structure", Microwave and optical Technology Letters, vol. 52, no. 1, (2009), pp. 17-20.

[7] P. N. Kumar, K. M. Vijay, T. Srinivas and K. J. Babu, “A Modified Back to Back E-Shaped Patch Antenna for 4G MIMO Communications", International Journal of Engineering and Technology, vol. 2, no. 3, (2012) March.

[8] K. J. Babu, K. S. R. Krishna and L. P. Reddy, "A Modified E Shaped Patch Antenna for MIMO Systems", International Journal on Computer Science and Engineering, vol. 02, no. 07, (2010), pp. 2427-2430.

[9] K. J. Babu, K. S. R. Krishna and L. P. Reddy, "A Multi Slot Patch Antenna for 4G MIMO Communications", International Journal of Future Generation Communication and Networking, vol. 4, no. 2, (2011).

[10] S. C. Gao, L. W. Li, M. S. Leong and T. S. Yeo, "Analysis of an H-shaped patch antenna by using the FDTD Method”, Progress in Electromagnetics Research, vol. 34, no. 1, (2001), pp. 165-187.

[11] R. Chair, C. Mak, K. Lee, K. Luk and A. A. Kishk, "Miniature wideband half U-slot and half E-shaped patch antennas", IEEE Transactions on Antennas and Propagation, vol. 53, no. 8, (2005), pp. 2645-2652.

[12] A. Ali and S. Thiagarajah, "A Review on MIMO Antennas Employing Diversity Techniques", Proceedings of the International Conference on Electrical Engineering and Informatics Institute Technology Bandung, Indonesia, (2007), pp. 17-19.

\section{Authors}

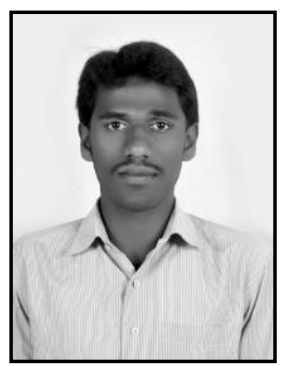

S. Anil kumar completed the B.Tech degree in Electronics and Communication Engineering in 2014 from the JNTU University, Kakinada. His areas of interest include Microstrip Antennas, MIMO Antennas, and Wireless communications. He is a member of ISTE. 


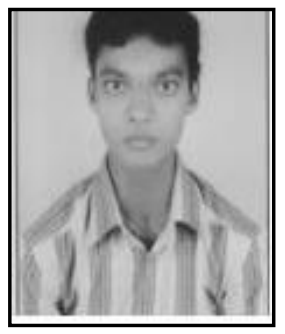

B. Kumara swamy completed the B.Tech degree in Electronics and Communication Engineering in 2014 from the JNTU University, Kakinada. His areas of interest include Microstrip Antennas, MIMO Antennas, and Wireless communications.

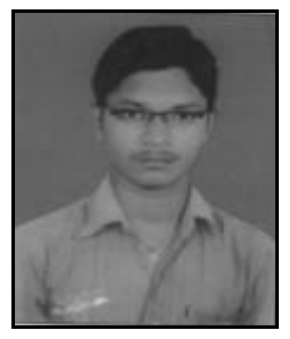

P. Vasanth kumar completed the B.Tech degree in Electronics and Communication Engineering in 2014 from the JNTU University, Kakinada. His areas of interest include Microstrip Antennas, MIMO Antennas, and Wireless communications. He is a member of ISTE.

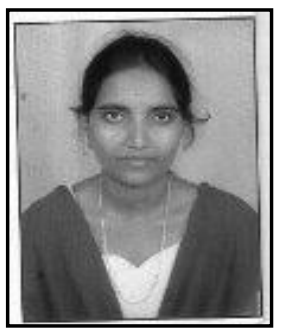

N. Yesu mariyamma completed the B.Tech degree in Electronics and Communication Engineering in 2014 from the JNTU University, Kakinada. Her areas of interest include Microstrip Antennas, MIMO Antennas, and Wireless communications. She is a member of ISTE.

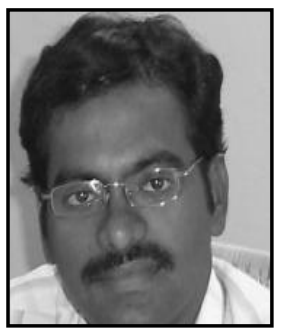

K. Jagadeesh Babu is working as Professor \& HOD in E.C.E Dept., at St. Ann's College of Engineering \& Technology, Chirala, INDIA. He obtained his PhD degree from E.C.E Dept, JNTU, Hyderabad in 2013. His areas of interest include Microwaves, MIMO Antennas, Wireless communications. He published more than 20 papers in reputed Journals like WILEY, SPRINGER, ELSEVIER, etc... He is a member of ISTE and IAENG. 
International Journal of Energy, Information and Communications Vol.5, Issue 4 (2014) 